\title{
Short, Instructional Module to Address Lifelong Learning Skills
}

\author{
Beth A. Todd \\ The University of Alabama
}

\section{Introduction}

Every engineering program must demonstrate their graduates' abilities to recognize the need for and engage in lifelong learning, as established in ABET 2000, Criterion 3(i). ${ }^{1}$ While faculty agree that lifelong learning is an important skill and one that is significant in the future careers of their graduates, they often have limited experience and resources for teaching this topic. For many engineering programs, it is hard to demonstrate where lifelong learning is contained in their curricula.

Since the addition of a "lifelong learning" course does not seem practical or attractive, a short module on this topic has been developed. The module is designed to fit logically into many upper division courses, particularly those involving open ended projects requiring the discovery of additional information. The classroom material will fit into three 50-minute class periods in a standard course. Although the module would take about a week of lecture away from a course, an improvement in the students' abilities should be seen further along in the curriculum to justify the time spent.

The module is organized to provide instruction on the objectives and associated tools as well as an opportunity to practice the new learning skills. This progressive development follows the format for teaching skills suggested by Woods et $\mathrm{al}^{2}$, where a skill is introduced in a context-free environment and then bridged and extended into the discipline material.

The module contains a set of PowerPoint slides that can be adapted for any discipline and used in the classroom. The classroom material incorporates active and cooperative learning exercises. There is an instructor's guide with background information on the topic, suggested in-class and homework assignments, and some suggestions for grading assignments on this "soft" skill.

The draft module was tested by a faculty member in computer science with a multi-disciplinary class of undergraduate student evaluators. Post module surveys (ranking topics on a scale of 1-5) were completed by the evaluators. Additional feedback was collected from the instructor and a faculty observer. This feedback has been used to improve the module.

The following sections describe the contents of the module. Later in the paper, the results of testing are presented.

\section{Pre-requisites}

This module assumes that the students have not had any previous instruction in the area of lifelong learning. However, students do not live in a vacuum. Experience with using this material in the classroom has shown that older, non-traditional students approach this material with more wisdom than students in their early 20's. This is particularly important to consider when selecting the "non-technical" homework assignment. The more familiarity that 
the instructor has with the students' backgrounds will lead to more satisfaction with this first homework assignment.

\section{Learning Objectives}

After discussion with other faculty and practicing engineers, it was determined that there are two fundamental aspects of lifelong learning: 1) knowing how to learn new material without taking a formal course or earning another degree, and 2) understanding what types of continuing education are available after graduation. The lifelong learning module was developed to focus on both of these issues. After completing this module, students should be able to:

a. Explain the importance of lifelong learning in an engineering or computer science career

b. Describe a process for learning new material

c. Given a situation, identify what learning is needed

d. Find appropriate resources in the library and on the web

e. List sources for continuing education opportunities

f. Assess their academic and professional development

g. Demonstrate that they can learn material on their own for a given assignment

The class periods are organized such that objectives a, b, and $d$ are covered the first day, objectives c, e, and f are covered during the second and third days, and objective $\mathrm{g}$ is related to the bridge assignment to take them back to their course material.

\section{Justification}

While it is important for students to recognize the need for lifelong learning, every faculty member knows that it is important for them to understand our purpose whenever we stray from the pre-defined course topic. The justification for the study of lifelong learning includes a wide variety of information as cited from several expert sources. Thorough discussion of all of this information in the classroom presentation will be excessively tedious. The justification material was compiled based on the assumption that an instructor will use only a selected portion of it.

The major justification topics include 1) avoiding obsolescence ${ }^{3,4}, 2$ ) the need to adapt to a changing society with a changing focus, 3 ) annual employment evaluations ${ }^{5}, 4$ ) employer surveys ${ }^{6}$, and 5) ABET criteria ${ }^{1}$. The discussion on obsolescence and a changing society includes examples from the author's background. Another instructor may want to modify the material to include his/her own personal example. That may be a more effective technique for keeping the students' attention.

\section{Process of Self-Learning}

Following the justification and learning objectives, the first day's class continues with the development of the steps in the process of self-learning. Students are divided into teams for an active learning exercise where they brainstorm on what these steps might be. After several teams report back to the class, a list of 'expert' steps in the process of self-learning is presented. The first class period ends with a discussion of sources of information and places to find sources of information. For engineers, sources are defined as things such as building codes, journal articles, newspaper articles, trade magazines, vendor catalogs, standards, etc. Students tend to think of sources of information as the Internet and the library. It is crucial for the instructor to emphasize 
that 1) there are a wide variety of sources of information that are useful to engineers and computer scientists, and 2) not all of the world's knowledge is contained on the Internet. The assignment at the end of the first class is a non-technical learning assignment where students are required to describe the process that they go through to complete the assignment and list the specific sources that they used as well as the location of those sources. Six examples of nontechnical learning assignments are included in the instructor's guide. Topics related to a student's future life experiences were considered, and they include such things as "Finding an apartment in a new city" and "Investing a large sum of money". Additional topics can be generated. The success of this assignment is related to whether or not the students already have experienced these things.

The second class period begins by discussing the results of the non-technical learning assignment and reviewing the important points of the first class period. This concludes the formal material related to the process of learning new material by ones self.

\section{Continuing Education}

The second class period continues with a discussion of the process for becoming a Professional Engineer, types of continuing education that are available following graduation, and the importance of using technical societies as a source of continuing education. This is followed by an active learning exercise where students are presented with a technical learning problem in which they must determine what needs to be learned and what type of continuing education can be used to learn that information. Six example topics are included in the instructor's guide, and these topics vary by major and level of student. The topics include "automotive safety" and "nuclear power generation". The homework assignment for the second day is to find specific places for continuing education for the problem that they discussed in class. They are also asked to bring copies of their resumes for the third class.

It was difficult to develop and present this portion of the module to a multi-disciplinary class. Currently the module contains information on the American Society of Mechanical Engineers (ASME), the American Society of Civil Engineers (ASCE), the Association for Computing Machinery (ACM), and the Institute for Electrical and Electronics Engineers (IEEE). Additional information can easily be added on the instructors' own professional society. It is recommended that when the module is taught in the context of the course that the relevant technical society be the focus of the discussion.

When the module is taught in conjunction with a regular course, an option for this technical learning assignment is to bridge back to the regular course material. This can be done either by assigning a project that requires students to gather information that is not provided in the regular lecture. Another option is to make this assignment involve a task that leads the students to a later project assignment.

\section{Professional Development}

Since the second class period follows from the premise of what new material an engineer may need to learn as his/her career progresses, the third class period considers what the student may need to learn to obtain an entry-level position. This class begins with a discussion of the last homework assignment and review of the main points of the second class period. This is 
followed by a discussion of what employers look for when hiring entry-level engineers. A couple of sample student resumes for John N. Gine and Sally R. Tide are included with the module, so that students can compare what John or Sally have to offer with what may be required in an entry-level position. An active learning exercise is given to plan for the types of professional development John or Sally need to be more competitive in the job market. The students are asked to go through a similar exercise with their own resume and begin to plan their own career development.

\section{Additional Material}

The instructor's guide describes the three class periods, active learning exercises, and homework assignments discussed above in much greater detail. It concludes with a discussion of grading rubrics for in-class and homework assignments. It is important when using in-class exercises that the students feel that the assignment will impact their grade in some way so that the assignment is completed. There is also discussion on assessing the impact of the lifelong learning module on the student's appreciation of lifelong learning. The instructor's guide concludes with a listing of references that were used during module development.

\section{Module Testing}

The lifelong learning module was one of 15 modules created to address soft skills in the engineering curriculum. A testing program was created for these modules. In this program, each module was taught by an instructor who did not develop the module. A group of engineering students in the sophomore through senior level with a range of GPAs and a variety of majors was hired to be the evaluators of the module. Six to 12 students took each of the modules as a weeklong class. In addition the module developer and another faculty evaluator sat quietly in the back of the room and evaluated the module. Students and evaluators were given a series of questionnaires for the particular module that they were working on. Some evaluators were given a series of questionnaires for a different module so that they would act as a control group. Many of the questions were rated on a 5-point strongly disagree (1) to strongly agree (5) scale. Results from the evaluation are presented below.

In the questionnaires, students were primarily asked about their confidence in performing each of the module objectives. A second set of questions asked whether or not they thought that these objectives were important in the practice of engineering. The instructor for the lifelong learning module was a faculty member in computer science. The faculty observer was from electrical and computer engineering, and the module developer was from mechanical engineering. Ten students evaluated the lifelong learning module, and twelve students were in the control group. All of the students participated in the cooperative education program. Post-module and control group results are available for lifelong learning module.

\section{Results}

The average student evaluations of their ability to perform the modules objectives are plotted in Figure 1. The objectives are listed in the same order as shown previously in the paper. A keyword for each of the objectives is included in the figure. Note that the control group scores their confidence in completing the module objectives higher than the students who took the module for several of the objectives: importance of lifelong learning, identifying missing information, finding resources, and demonstrating their ability to learn new material. Note also 
that both groups give each of these topics a score greater than 4 . The students who completed the module score higher than the control group on listing the steps in the learning process, knowledge of continuing education, and ability to access their professional development. Note that the control group gave each of these topics a score between 3 and 4 .

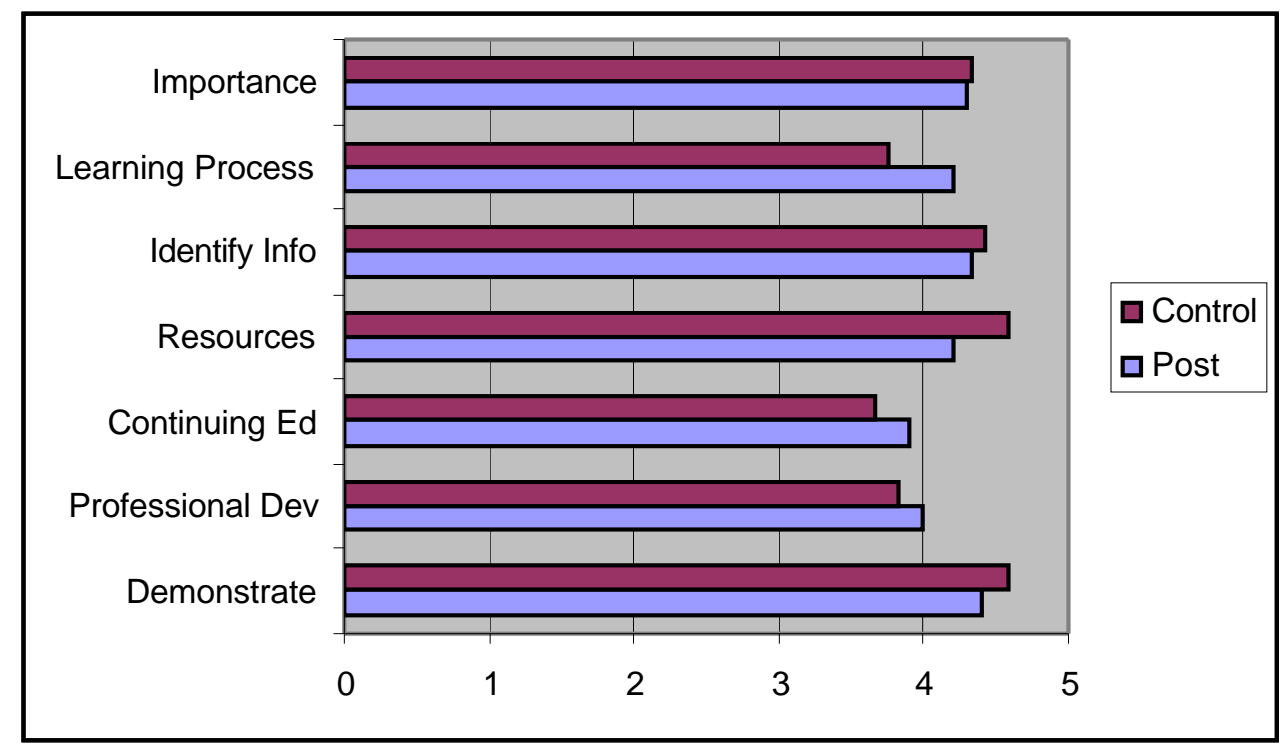

Figure 1. Student rating of their ability to perform each of the module objectives

The average student evaluations of the significance of the modules objectives are plotted in Figure 2. Once again the control group scored higher on each of these objectives than the students who took the module except for the importance of continuing education. Note again that both groups rated all of the other objectives with a score of 4 or higher.

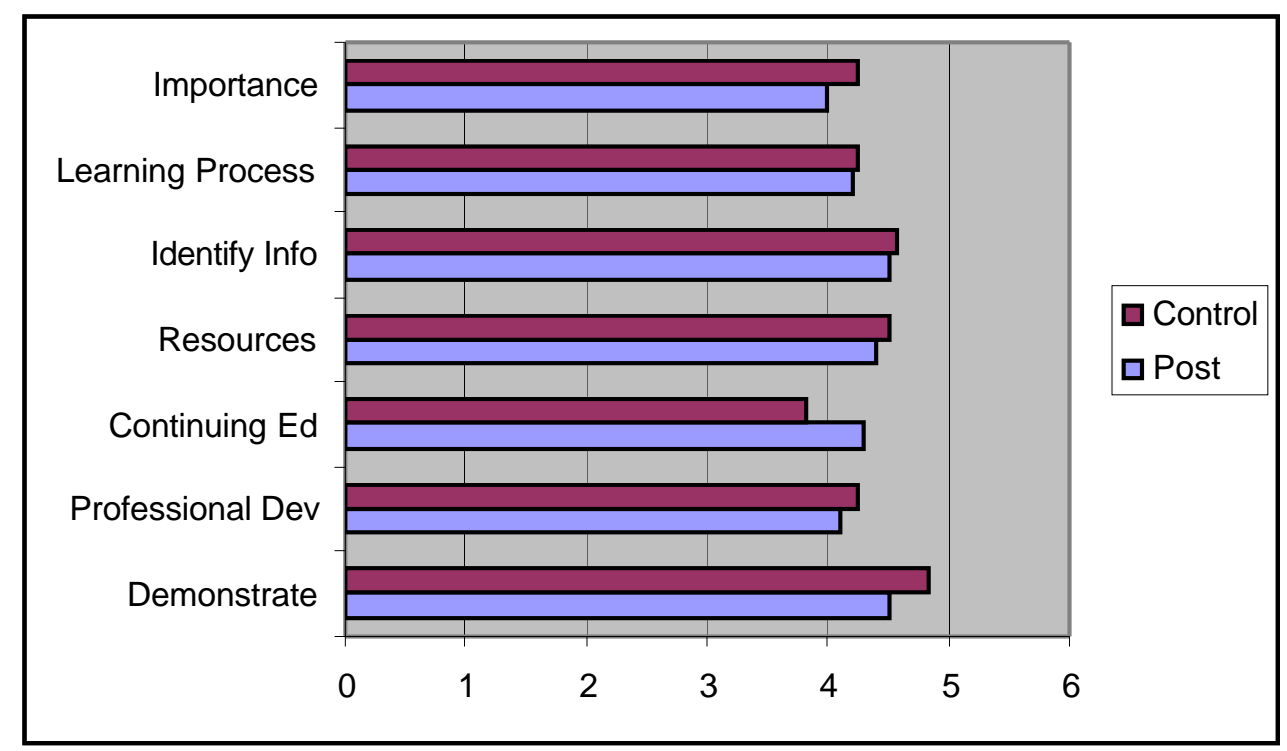

Figure 2. Student rating of the significance of each of the module objectives 


\section{Discussion}

Results of the student evaluations of the modules show little difference between the control group and the students who took the module. This may be for several reasons.

This result may be due partly to differences between the two groups. The students who took the lifelong learning module had this class in the mornings. The students who served as the control group were taking another class in the afternoon. While the difference between morning and afternoon should not make a difference, it was noted on several of the modules that the afternoon evaluators gave higher ratings to modules. A better comparison would have been to give the morning students a pre-module and a post-module evaluation. Unfortunately this was not done before the module was given to them.

A much more significant result is related to the high value of almost all of these scores. On average both groups of students agreed that almost all of the topics of lifelong learning were significant and were confident that they could perform these tasks. This may provide evidence that we are teaching lifelong learning to our students in our curricula even though we are not doing it explicitly. In the written comments given by the students, one wrote, "it (lifelong learning) should be the backbone of every engineering course and has been in my experience".

\section{Conclusion}

A three-class period module has been created on the topic of lifelong learning. The module contains a set of PowerPoint slides, an instructor's guide, suggested homework assignments, and additional materials for a faculty member who would be interested in using it. While the module is still undergoing improvement, it is at a stage where it can be used by other faculty. The module can be accessed at

http://www.ece.ua.edu/faculty/rpimmel/public_htlm/ec2000-modules.

The module has been tested with a randomly selected group of engineering students in various majors. Their evaluation of the module's learning objectives on a "strongly disagree (1)" to "strongly agree (5)" scale was presented and discussed. Results show that participation in the module did not benefit the students who took it by very much over a control group. However, the results do show that students in both groups were confident in their ability to perform the module objectives. These results show that these students have developed an appreciation for and the ability to engage in lifelong learning.

\section{Bibliography}

1. ABET, (2000) Criteria for Accrediting Engineering Programs, http://www.abet.org/images/eac_criteria_b.pdf, January 1, 2002.

2. Woods et al., (1997), Developing Problem Solving Skills: The McMaster Problem Solving Program”, J. Eng. Ed., 86:74-91.

3. Marra, R.M., K.Z. Camplese, T.A. Ligzinger, (1999), "Lifelong Learning: A Preliminary Look at the Literature in View of EC 2000", Frontiers in Education Conference Proceedings, Vol. 1, 11a1.7-11a1.12.

4. SAE, International, (2001) SAE Engineering Academies, http://www.sae.org/contedu/academy.htm, June 8, 2001. 5. Wolff, Shelley A.M., (2000) "Perspectives on Lifelong Learning: HNTB's Career Development Center", Proceedings, Society of Women Engineers National Conference, Washington DC. 
6. Benefield et al, (1997), "Quality Improvement in College of Engineering Instructional Programs", J. Eng. Ed. 86:5764.

\section{Acknowledgments}

This work was supported by NSF Award Number EEC-9802942.

Beth A. Todd, Ph.D.

Beth Todd is an Associate Professor in the Department of Mechanical Engineering at the University of Alabama. She received her B.S. degree in Engineering Science from Penn State University and her graduate degrees in Applied Mechanics and Mechanical and Aerospace Engineering from the University of Virginia. Dr. Todd's area of research is in biomedical engineering, primarily related to the design of assistive technology and orthopedic biomechanics. 